\title{
Antimicrobial resistance: global problems need global solutions
}

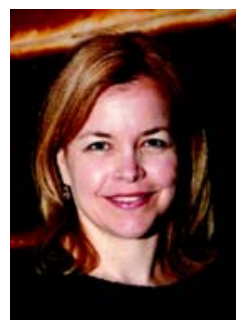

Susan Maddocks

Deputy Editor

mja@mja.com.au

Competing interests: I am a member of ASID.

doi: 10.5694/mjal3.c0318 uch has been written about antimicrobial resistance and the measures we must take to prevent an era in which infections become untreatable. Despite these longstanding concerns, there has been a steady rise in antimicrobial resistance globally, threatening the effectiveness of increasing numbers of antimicrobial classes against broadening species of microorganisms.

Do we continue on our current path until no effective antimicrobials are available, the pressure on microorganisms is slowly reduced, and resistance wanes over time? If so, we face a period during which many people will die with untreatable infections. Or do we act now?

In the spirit of optimism that action now can still make a difference, we publish in this issue several articles to be presented at this week's combined Australasian Society for Infectious Diseases (ASID) and Communicable Disease Control conference, which address the breadth of antimicrobial resistance issues we currently face.

In their editorial, Looke and colleagues from the ASID Council (page 243) describe the growing threat of multiresistant gram-negative bacteria, a new "Red Plague", engendered by the ability of resistance genes to move freely between bacterial species, across borders and, through global travel and trade, around the world. An example of a multiresistant gram-negative pathogen causing disseminated infection after a routine surgical procedure is described by Roberts and colleagues (page 282). This infection was caused by an organism thought to have been acquired innocuously during regular overseas travel. In the same vein, research by Kotsanas and colleagues (page 267) describes the difficulty in eliminating an environmental source of resistance-carrying plasmids that had been implicated in several clusters of infection in an intensive care unit.

The ways to deal with resistance are seemingly straightforward: halting unnecessary use of antimicrobials, limiting broad-spectrum antimicrobial use through stewardship programs, and enforcing basic preventive infection control measures that relate to hygiene, sterile technique and isolation of infectious carriers, as well as reducing antimicrobial use in veterinary and animal production sectors. As of January 2013, antimicrobial stewardship programs are a requirement for hospital accreditation in Australia, but do they actually work? Cairns and colleagues (page 262) describe an audit of antimicrobial use before and after an antimicrobial stewardship program in a tertiary hospital in Victoria. While immediately successful in reducing broad-spectrum antibiotic use, there was a trend towards a subsequent rebound, the venture has not yet been proven cost-effective, and long-term outcomes such as reductions in antimicrobial resistance cannot yet be shown. More work may be needed to convince all stakeholders of the importance of implementing these measures.

It may yet be the simplest preventive measures that have the greatest effect for the least cost. Coatsworth and colleagues (page 285) describe a case of probable iatrogenic prosthetic shoulder infection attributable to an intra-articular injection performed by a proceduralist not wearing a mask. Have we come to depend so much on the panacea of the antimicrobial that we have forgotten the lessons of

Semmelweis, Pasteur and Lister? Prevention of infection must be as important as treatment, and this will require effort on a global scale. In the developing world, resistance is becoming endemic and our global interactions mean we cannot act in isolation and expect resistance to disappear.

Ghafur (page 251) urges us to behave like microbes and "unite or perish". He calls for global, cross-border action and describes efforts in India to tackle the now very serious threat of gram-negative resistance by bringing together members from across the medical, political, industrial and community divide to create the Chennai Declaration.

We can all learn from this effort, but the real challenge is to institute the measures we know are needed and to show that they can work. If we do, we may one day write about the success story that is global collaboration, reduced resistance, better infection control and improved human health.

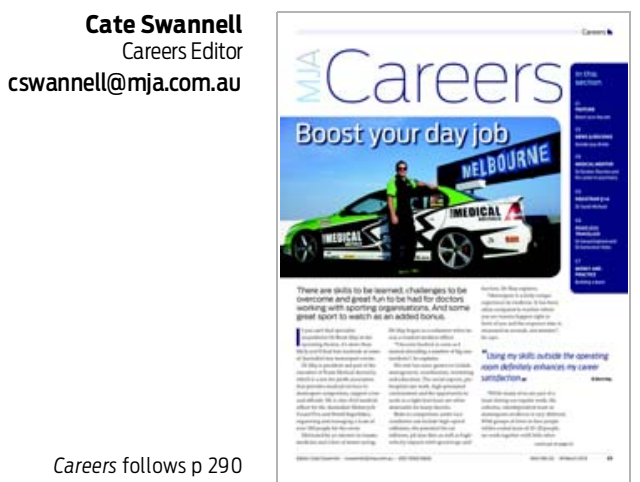

Careers follows $\mathrm{p} 290$

\section{Outside the box}

Dr Brent May found the perfect way to combine two loves - trauma medicine and motor sport — by becoming involved in Team Medical Australia, providing medical services to motorsport competitors and crews. Karen Burge spoke to Dr May and other sports-mad practitioners who give up their spare time to fuel their passion outside the surgery (page C1). Two other general practitioners nurturing their creative side are Dr Gerard Ingham and Dr Genevieve Yates, who wrote and perform in GP the musical, which takes on a short season at the Melbourne International Comedy Festival next month. Cate Swannell spoke to them both about how music and creativity make them better doctors and educators (page C6). In our Money and Practice section, Annabel McGilvray investigates the gentle art of team-building and its place in the running of a successful, happy general practice (page C7). Our Medical Mentor is Dr Gordon Shymko and our Registrar Q\&A puts Dr Sarah Michael under the spotlight (page C5). 